\title{
Fuzzy Logic Control of DFIG to Eliminate Unbalances in Weak Grid System
}

\author{
V.Suresh ${ }^{1}$, D. J. V Prasad ${ }^{2}$ \\ ${ }^{I} P G$ Scholar, Department of Electrical and Electronics Engineering SRKR Engineering College, Bhimavaram- \\ 534204, West Godavari, Andhra Pradesh, India. \\ ${ }^{2}$ Professor, Department of Electrical and Electronics Engineering SRKR Engineering College, Bhimavaram- \\ 534204, West Godavari, Andhra Pradesh, India
}

\begin{abstract}
This paper presents a mathematical model of a doubly fed induction generator (DFIG) in the positive synchronous reference frame under distorted grid voltage conditions eith the help of fuzzy logic controller. The oscillations of the DFIG's electromagnetic torque and the instantaneous stator active and $r$ active powers are fully described when the grid voltage is harmonically distorted. Four alternative control targets are proposed to improve the system responses during grid harmonic distortions. A new rotor current control scheme implemented in the positive synchronous reference frame is developed. The control scheme consists Fuzzy logic controller and a resonant controller consequently, the fundamental and the fifth- and seventh-order components of rotor currents are directly regulated by the Fuzzy-R controller without sequential-component decompositions. The feasibility of the proposed control strategy is validated by simulation studies on a 2.0-MW wind-turbinedriven DFIG system. Compared with the conventional vector control scheme based on standard PI current controllers, the proposed control scheme leads to significant elimination of either DFIG power or torque oscillations under distorted grid voltage conditions.
\end{abstract}

Index Terms - Current control, distorted voltage, doubly fed induction generator (DFIG), harmonics, and modeling.

\section{Introduction}

The global electrical energy consumption is rising and there is steady increase of the demand on power generation. The existing conventional energy sources are depleting .So alternative energy source investment are becoming more important now a days. Wind electrical generation systems are recently getting lot of attention, because they are most cost competitive, environmental clean and safe renewable power source, as compared to fossil fuel and nuclear power generation. The depletion reserves, increase in demand, and certain factors in world politics have together contributed to a sharp rise in the cost of thermal power generation. Many places also do not have the potential for generating hydel power. Nuclear power generation was once treated with great optimism, but with the knowledge possible leakage from nuclear power plants, most countries have decided not to install them anymore. The growing awareness of these problems led to heightened research efforts for developing alternative sources of energy for generation of electricity. The most desirable source would be one that is non- pollutant, available in abundance and renewable and can be harnessed at an acceptable cost in both large - scale and small scale systems. The most promising source satisfying all these requirements is wind, a natural energy source. Wind is a form of solar energy. The uneven heating of the atmosphere by the sun, the irregularities of the earth's surface, and rotation of the earth cause winds. The maximum extractable energy from the 0-100 m layer of air has been estimated to be the order of $1012 \mathrm{KWh} / \mathrm{annum}$, which is of the same order as hydroelectric potential. Over $1700 \mathrm{MW}$ of wind generators are installed worldwide, Current generation is of 100 billion KWh of energy annually. Recent evolution of power semiconductors and variable frequency drive technology has aided the acceptance of variable speed generation systems. In spite of additional cost of power electronics and control, the total energy captured in a variable speed wind turbine system is larger and therefore the lifecycle cost is lower than with fixed speed drives. Denmark was the first country to erect windmill and the top five countries in the world to have the highest installed wind power capacity are Germany, Spain, Denmark, U.S.A and India respectively. In this paper fuzzy logic principles have been used. Fuzzy logic is a powerful and versatile tool for representing imprecise, ambiguous and vague information. It also helps to model difficult, even intractable problems. In this paper, all the control algorithms have been validated by Matlab simulation study and system performance has been evaluated in detail. WIND energy, recognized as the main contribution to low carbon societies, has become one of the subjects of much recent research and development globally. Recently, more and more modern wind turbines are being installed in distribution and rural grids with low $X / R$ ratios, and in developing countries, where the distribution grids are quite weak. As a result, the application of wind generation systems based on modern power electronics has promoted the development of new functionalities for wind turbines, i.e., voltage or frequency regulation, islanding operation, 
and uninterruptable operation under nonideal grid voltage conditions including symmetrical voltage dips, network unbalance, and harmonically distortions. Among the various types of wind turbines, the variable speed wind turbines based on the doubly fed induction generator (DFIG), which have many advantages over the fixed speed induction generators or fully fed synchronous generators with full-sized converters, including variablespeed constant frequency (VSCF) operation, reduced flicker, independent control capabilities for active and reactive powers, and relatively lower converter cost and power losses, have attracted extraordinary attention by researchers and manufacturers all over the world [1]. These excellent merits are primarily achieved via the control of a rotor-connected back-to-back voltage-source converter, which is typically rated at around 30\% of the generator rating for a given rotor speed range of $0.75-1.25$ p.u. under normal operation conditions. However, since the DFIG's stator is directly connected to the grid via step-up transformers and the rating of the grid-side and rotor-side converters is limited, the DFIG generation system is pretty sensitive to any grid disturbances [2]. The steady-state and transient response of DFIG-based wind power generation system under balanced [1]-[4] and unbalanced [5]-[12] grid voltage conditions have been well understood. Hu et al. [9] and [10] proposed proportional-integral (PI) plus resonant tuned at twice the grid frequency current controllers for both grid-and rotor-side converters. As a result, simultaneous elimination of torque and total active power oscillations at twice the grid frequency have been achieved due to the precise regulation of both positive- and negative-sequence currents when the network voltage is unbalanced. Whereas, voltage harmonics in the grid voltage were not considered Practically, both transmission and distribution networks can also have voltage harmonic distortions. For instance, standards IEEE-519-1992 [13] and ER G5/4-1 [14] have, respectively, recommended different practices and requirements for harmonic control in electrical power systems. Both of them allow individual voltage harmonics, especially fifth- and seventh-order components, to exist up to $3 \%$ in the voltage level of 6.6, 11 , and $20 \mathrm{kV}$. As indicated in [15] and [16], the presence of harmonics in the supply system results in torque pulsations and increased copper and iron losses in electrical machines. As with induction generators, if voltage harmonics are not taken into account by a DFIG's control system, highly distorted stator/rotor currents, and significant torque and power oscillations could result [17]. A DFIG-based wind turbine without distorted voltage control might have to be disconnected from the grid during grid voltage harmonic distortions. However, standards recommend wind farms to withstand a certain voltage harmonics without tripping. The system control and operation of wind-turbine-driven DFIG under distorted grid voltage conditions were initially studied in [17]. A harmonics control scheme with relatively lower dynamics was added to the main rotor current controller. The harmonics control scheme was based on low-pass finite-impulse response (FIR) filters and integral regulators, each of which was responsible for regulating the selected sequential components of rotor currents, respectively, within three grid cycles. As a result, the steady-state harmonic components in the stator currents were eliminated, whereas, for the work reported, the impact of distorted stator voltage on the stator and rotor currents has not been fully defined. In addition, the relationships between the oscillations of the generator torque, the stator active/reactive powers, and the rotor currents have not been fully established. Furthermore, the analysis was carried out in the synchronous reference frame, which inevitably resulted in the control variables being at six times the grid frequency. In Hu et al.'s previous work [18], an improved current control scheme was presented using a PI plus multifrequency resonant (PI + MFR) controller for a grid-connected voltage-source converter under imbalanced and distorted supply voltage conditions. The control scheme provides pretty good regulation for positive/negative-sequence currents as well as fifth/seventh order current harmonics. As a result, the PI + MFR control scheme can be directly applied to the grid-side converter of DFIG system when the network is distorted. While for the rotor-side converter under distorted grid voltage conditions, this paper investigates ways to improve the control and operation of wind-turbine-driven DFIG generation systems. In the stator voltageoriented positive $(d q)+$ and harmonic $(d q) 5-,(d q) 7+$ reference frames, the mathematical model of a DFIG system under fifth- and seventh-order harmonically distorted grid supply is developed. Based on the developed model, the relationships between the generator torque, the stator active/reactive powers, and the sequential stator voltages/fluxes and rotor currents are fully established. Different control targets are identified, and the corresponding reference values of rotor's fundamental and harmonic currents are provided. A new rotor current control scheme implemented in the $(d q)+$ reference frame is developed. The control scheme consists of a PI regulator and a harmonic resonant compensator tuned at six times the grid frequency, so as to directly regulate the fundamental and the fifth- and seventh-order components of rotor currents without sequential component decompositions. Finally, simulation results on a 2.0 MW DFIG system are provided to demonstrate the effectiveness of the proposed control strategy.

\section{A. DFIG Model}

\section{Dynamic Modeling Of Dfig}

Under balanced and distorted grid voltage conditions, no zero- sequence component is assumed, and the positive sequence of the fundamental and the harmonics at the frequencies of $-5 \omega_{1}$ and $7 \omega_{1}$ are taken into consideration in this paper. In the stationary $\alpha \beta$ reference frame, the voltage, current, and flux can be 
decomposed into the positive-sequence component of the fundamental and the harmonic components of $-5^{\omega_{1}}$ and $7 \omega_{1}[18]$

$$
\begin{aligned}
F_{\alpha \beta} & =F_{\alpha \beta}(\mathrm{t})+F_{\alpha \beta 5-}(\mathrm{t})+F_{\alpha \beta 7+}(\mathrm{t}) \\
& =\left|F_{\alpha \beta+}\right| e^{I\left(\omega_{2} \mathrm{t}+\varphi_{4}\right)}+\left|F_{\alpha \beta 5-}\right| e^{J\left(5 \omega_{2} \mathrm{t}+\varphi_{2}\right)}+\left|F_{\alpha \beta \gamma}\right| e^{I\left[\left(7 \omega_{2} \mathrm{t}+\varphi_{7}\right)\right.}
\end{aligned}
$$

Where $\varphi_{+}, \varphi_{5}$ and $\varphi_{7}$ are the respective initial phase shift for the Positive sequence of the fundamental and harmonic components Of $-5 \omega_{1}$ and $7 \omega_{1}$.

As shown in Fig.1, for the positive synchronous $(d q)^{+}$

reference frame, the $d+$-axis is aligned with the positive-sequence stator voltage rotating at the angular speed of $\omega_{1}$. While for the $(d q)^{5-}$ and $(d q)^{7+}$ reference frames, as can be seen from Fig. 1, their $d^{d^{5-}}$ and $d^{d^{7+}}$ axes rotate at the angular speeds $-5 \omega_{1}$ and $7 \omega_{1}$, respectively, with the phase angles to the $\alpha$-axis being $-\theta_{5}$

And $\theta_{7}$

According to Fig. 1, the transformations between the $\alpha \beta,(\alpha \beta)^{\gamma},(d q)^{+},(d q)^{5-}$ and $(d q)^{7+}$ reference frames are given as Follows:

$$
\begin{aligned}
& F_{d q}^{+}=F_{\alpha \beta} e^{-j \omega_{2} t} \quad F^{\Delta+} d q=F^{\gamma+} d q^{e^{-j 12 \omega_{1} t}} \\
& F^{+} d q=F^{r+}{ }_{\alpha \beta} e^{-J\left(\omega_{1}-\omega_{r}\right\}} \\
& F^{\nu-} d q=F^{7+}{ }_{\alpha \beta} e^{-j 5 \omega_{2} t} \quad F^{+} d q=F^{5-}{ }_{d q} e^{-j 6 \omega_{2} t}
\end{aligned}
$$

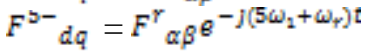

$$
\begin{aligned}
& F^{\gamma+} d q=F_{\alpha \beta} e^{-j 7 \omega_{2} t} \quad F^{+} d q=F^{7+} d q^{e^{-j 6 \omega_{2} t}} \\
& F^{\delta+} d q=F_{d q}^{\gamma} e^{-J\left(J \omega_{1}-\omega_{f}\right) t}
\end{aligned}
$$

where superscripts,$+ 5-, 7+$, and $r$ represent the $(\alpha \beta)^{r},(d q)^{+},(d q)^{5-}$ and $(d q)^{7+}$ reference frames, respectively

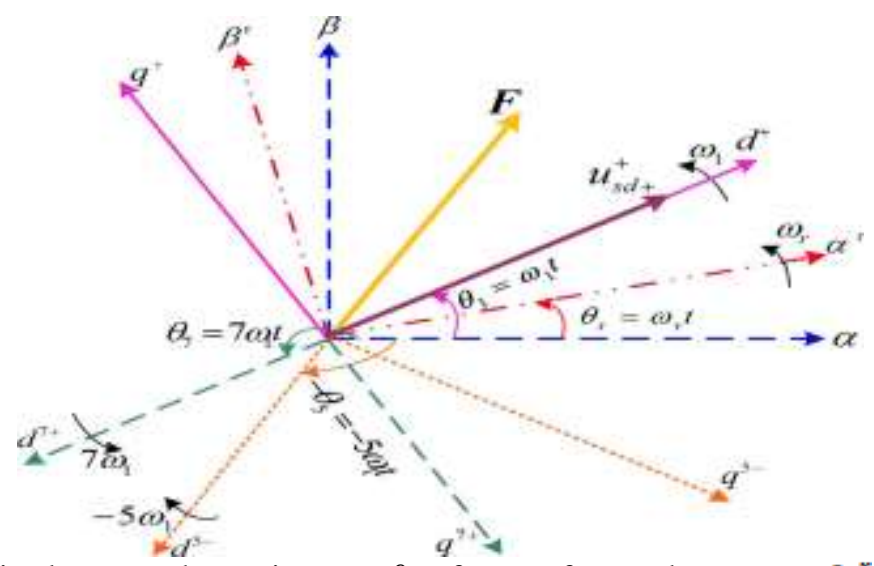

Fig. 1. Spatial relationships between the stationary $\alpha \beta$ reference frame, the rotor $(\alpha \beta)^{\gamma}$ reference frame, and the $(d q)^{+},(d q)^{5-}$ and $(d q)^{7+}$ reference frames.

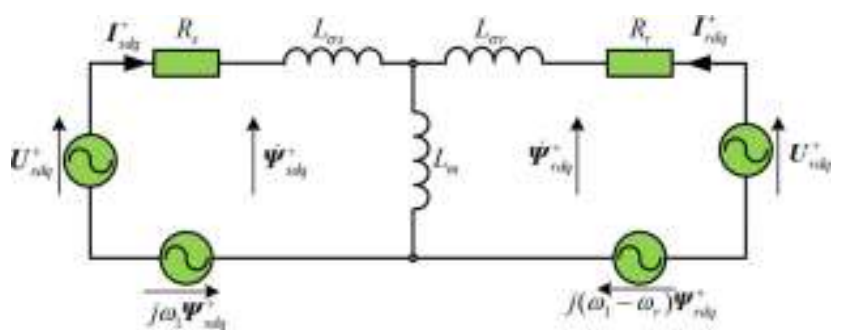

Fig. 2. T-representation of the DFIG equivalent circuit in the positive synchronous $(d q)^{+}$reference frame rotating at the speed of $\omega_{1}$.

The equivalent circuit of a DFIG in the $(d q)^{+}$reference frame

Is shown in Fig. 2. 
According to Fig. 2, $\varphi^{+}{ }_{s d q}$ and $\varphi^{+}{ }_{r d q}$ the stator and rotor flux can be represented, respectively, by

$$
\begin{aligned}
& \varphi^{+}{ }_{s d q}=L_{s} I^{+}{ }_{s d q}+L_{m} I_{r d q}^{+} \\
& \varphi_{r d q}^{+}=L_{m} I_{s d q}^{+}+L_{r} I_{r d q}^{+}
\end{aligned}
$$

From Fig. 2, the stator and rotor voltages $U^{+}{ }_{s d q}$ and $U^{+}{ }_{r d q}$ in the $(d q)^{+}$reference frame can be expressed as follows:

$$
\begin{aligned}
& U_{s d q}^{+}=R_{s} I_{s d q}^{+}+\frac{d \varphi^{+}{ }_{s d q}}{d t}+\mathrm{j} \omega_{s} \varphi^{+}{ }_{s d q} \\
& U_{r d q}^{+}=R_{s} I^{+}{ }_{r d q}+\frac{d \varphi^{+}{ }_{r d q}}{d t}+\mathrm{j} \omega_{s} \varphi^{+}{ }_{r d q}
\end{aligned}
$$

where $R_{g}$ and $R_{\mathrm{r}}$ are stator and rotor resistances, $L_{g}=L_{\delta_{g}}+L_{m}$ $\& L_{r}=L_{\delta_{r}}+L_{m}$ are total self-inductances of stator and rotor winding $L_{\mathscr{B}_{r}}, L_{\sigma_{g}} \& L_{m}$ are stator and rotor leakage inductances and mutual inductance, $\omega_{1}$ respectively, is synchronous angular speed, $\omega_{F}$ is rotor angular speed, and $\omega_{g}=\omega_{1}-\omega_{y}$ is slip angular speed.

According to (1), (2) and Fig. 1, the stator and rotor current, voltage, and flux vectors can be expressed in terms of their positive sequence of the fundamental and the harmonic components of $-5^{\omega_{1}}$ and $7^{\omega_{1}}$ in the synchronous $(d q)+$ reference frame as follows:

$$
\begin{aligned}
& F_{s d q}^{+}=F_{s d q+}^{+}+F_{s d q 5-}^{+}+F_{s d q 7+}^{+} \\
& \quad=F_{s d q+}^{+}+F_{s d q-}^{5-} e^{-j 6 \omega_{1} t}+F_{s d q}^{7+} e^{j 6 \omega_{1} t} \\
& F_{r d q+}^{+}=F_{r d q+}^{+}+F_{r d q 5-}^{+}+F_{r d q 7+}^{+} \\
& =F_{r d q+}^{+}+F_{r d q-}^{5-} e^{-j 6 \omega_{1} t}+F_{r d q}^{7+} e^{j 6 \omega_{1} t}
\end{aligned}
$$

where subscripts,$+ 5-$, and $7+$ represent the positive sequence of the fundamental component and the harmonic

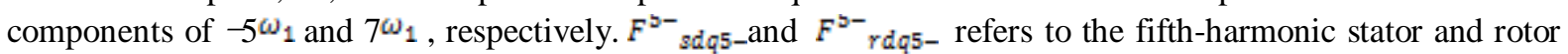
quantities in the $(d q)^{5-}$ reference frame. It is worth noting that the harmonic components of $-5 \omega_{1}$ and $7 \omega_{1}$ both behave as the ac components pulsating at the frequencies of $\pm 6^{\omega_{1}}$ in the $(d q)+$ reference frame.

According to (3) and (4), the rotor flux and stator current can be calculated as follows:

$$
\begin{aligned}
& \varphi^{+}{ }_{r d q}=\frac{L_{s \varphi^{+}}{ }^{*} L_{q}}{L_{z}}+\sigma L_{y} I^{+} r d q
\end{aligned}
$$

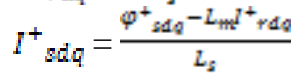

Where

$$
\sigma=1-{ }^{L^{2}}{ }^{2} / L_{s} L_{y}
$$

$$
\text { is the leakage factor. }
$$

Substituting (8) into (6) yields the rotor voltage in the $(d q)+$ Reference frame as follows:

$$
\begin{aligned}
& U^{+}{ }_{r d q}=R_{\gamma} I^{+}{ }_{r d q}+\frac{d}{d t}\left(\frac{i_{m q}}{L_{q}} \varphi^{+}{ }_{g d q}+\sigma L_{\gamma} I^{+}{ }_{r d q}\right)+\quad j \omega_{g}\left(\frac{I_{m}}{L_{q}} \varphi^{+}{ }_{g d q}+\sigma L_{\gamma} I^{+}{ }_{r d q}\right)
\end{aligned}
$$

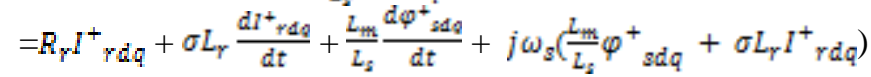

B. Active and Reactive Power Flow

According to (7a), (5) could be rewritten as follows:

$$
\begin{aligned}
& U^{+}{ }_{r d q} \otimes d\left(\varphi^{+}{ }_{g d q+}+\varphi^{5-}{ }_{g d q+} e^{-j 6 \omega_{2} t}+\varphi^{7+}{ }_{g d q 7+} e^{j 6 \omega_{2} L^{2}}\right) / d t+ \\
& \left.j \omega_{1 !} \varphi^{+}{ }_{a d q+}+\varphi^{5-}{ }_{g d q+} e^{-j 6 \omega_{2} t}+\varphi^{7 t}{ }_{g d q 7+} e^{j 6 \omega_{2} t}\right)+ \\
& \left.=j \omega_{1} \varphi_{g d q+}^{+}-5 \varphi^{5-}{ }_{g d q 5+} e^{-j 6 \omega_{2} t}+\varphi^{7+}{ }_{g d q 7+} e^{j 6 \omega_{2} t}\right)
\end{aligned}
$$

Under balanced and distorted grid voltage conditions, the

DFIG's stator output instantaneous active and reactive powers

Can be expressed as follows: 
$P_{g}+j Q_{s}=-\frac{a}{2} U^{+}{ }_{a d q} I^{+}{ }{ } d q$

Where $\boldsymbol{I} \boldsymbol{I} s d q$ is the conjugated space vector of $\boldsymbol{I}+$

$S d q$. Substituting (9) and (11) into (12) and decomposing the active and reactive powers into different pulsating components yield

$$
\begin{gathered}
P_{s}=P_{s 0}+P_{g \cos 6} \cos \left(6 \omega_{1} t\right)+P_{s \sin 6} \sin \left(6 \omega_{1} t\right)+P_{s \cos 12} \cos \left(12 \omega_{1} t\right)+P_{g \sin 12} \sin \left(12 \omega_{1} t\right) \\
Q_{s}=Q_{s 0}+Q_{s \cos 6} \cos \left(6 \omega_{1} t\right)+Q_{s \sin 6} \sin \left(6 \omega_{1} t\right)+Q_{g \cos 12} \cos \left(12 \omega_{1} t\right)+Q_{g \sin 12} \sin \left(12 \omega_{1} t\right)
\end{gathered}
$$

Where (14a)-(14c), shown at the bottom of the page,

Hold.

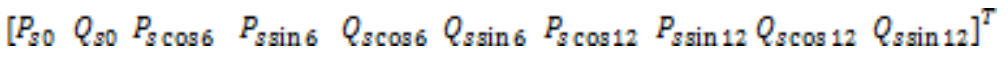

$$
\begin{aligned}
& =-\frac{a}{2 L_{2}} \mathrm{~A}\left[\varphi^{+}{ }_{s d+} \varphi_{s q+}^{+} \varphi_{s d 5-}^{D-} \varphi_{s d 7+}^{+} \varphi_{s d 7+}^{+} \varphi_{s d 7+}^{+}\right]^{Y}
\end{aligned}
$$

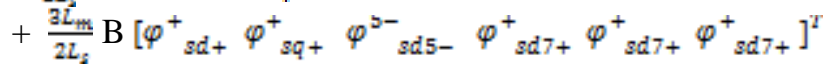

And

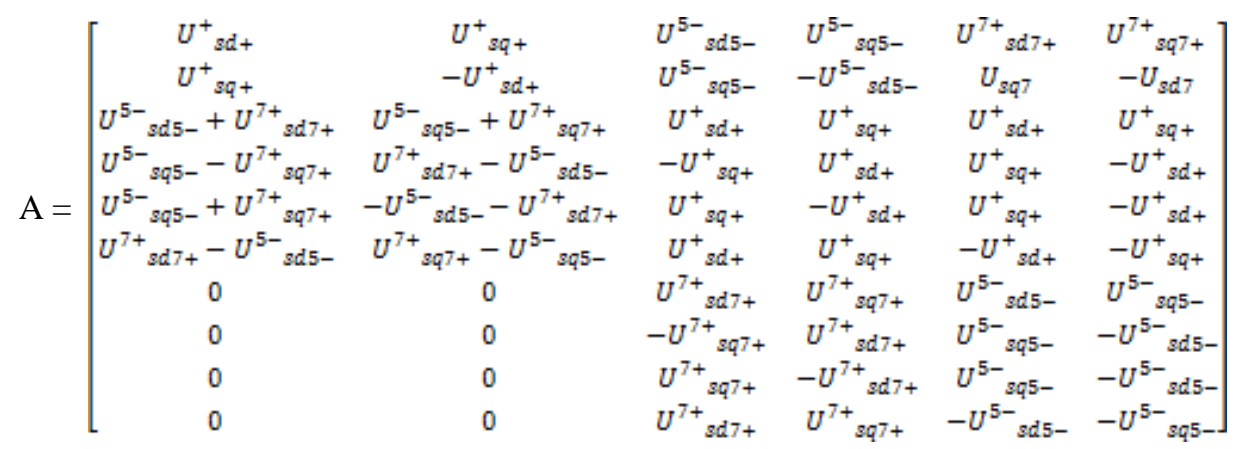

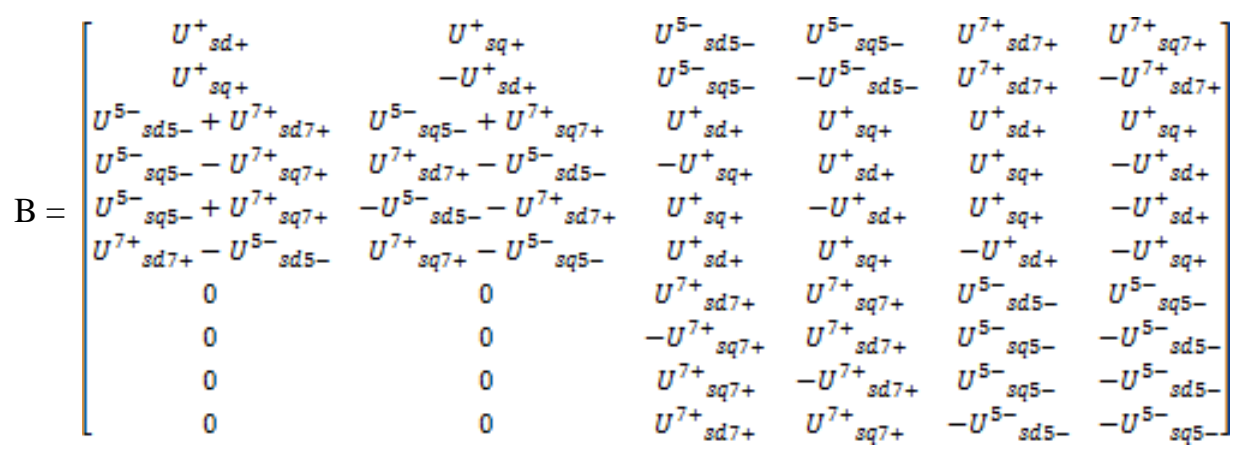

From Fig. 2, the electromagnetic power equals to the sum of the power outputs from the equivalent voltage sources $j \omega 1 \psi+s d q$ and $j(\omega 1-\omega r) \psi+r d q$. Thus, we can obtain

$$
\begin{aligned}
& P_{e}=-1.5 R_{e}\left[\mathrm{j} \omega_{1} \varphi^{+}{ }_{d d q} \hat{I}^{+}{ }_{s d q}+\mathrm{j}\left(\omega_{1}-\omega_{\gamma}\right) \hat{I}_{r d q}^{+}\right] \\
& \quad=-1.5 \omega_{y} L_{m} / L_{g} \times I_{m}\left(\varphi^{+} \hat{I}^{+} \hat{I}^{+} r d q\right) \\
& =P_{e 0}+P_{e \cos 6} \cos \left(6 \omega_{1} t\right)+P_{e \sin 6} \sin \left(6 \omega_{1} t\right)+P_{e \cos 12} \cos \left(12 \omega_{1} t\right)+P_{g e} \sin \left(12 \omega_{1} t\right) \\
& (15)
\end{aligned}
$$

Where (16a) and (16b), shown at the bottom of the next page, hold. The electromagnetic torque of the DFIG is calculated as follows: 
(16)

$$
T_{e}=\frac{P_{Q}}{w_{F_{p}}}
$$

$$
\begin{aligned}
& {\left[\begin{array}{lllll}
P_{e 0} & P_{e \cos 6} & P_{e \sin 6} & P_{e \cos 12} & P_{e \sin 12}
\end{array}\right]^{T}}
\end{aligned}
$$

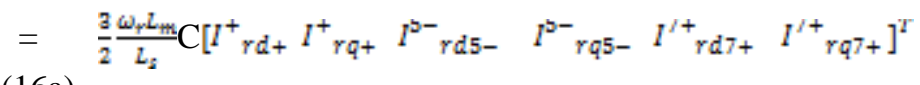

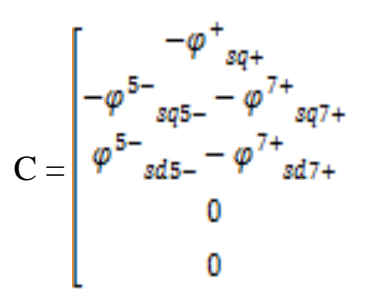

$$
\begin{gathered}
\varphi^{+}{ }_{8 d+}{ }_{\varphi^{5-}}{ }^{8 d 5-}+\varphi^{7+}{ }_{8 d 7+} \\
\varphi^{5-}{ }_{8 q 5-}-\varphi^{7+}{ }_{8 q 7+} \\
0 \\
0
\end{gathered}
$$
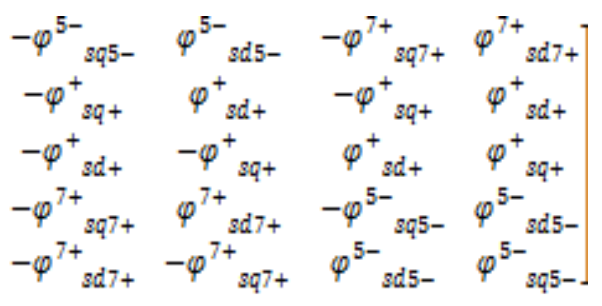

(16b)

Where $p$ is the number of pole pairs.,

As represented in (14) and (16), under distorted grid voltageconditions, the instantaneous active power output from the DIFG's stator contains five components, viz., the dc average

term, the cosine and sine terms of 6th and 12th the grid frequency.It is the same with the stator output reactive power and electromagnetic torque. Besides, it is worth noting from (14) and (16) that the pulsating terms of 12th the grid frequency are only calculated from the fifth- and seventh-order harmonic components of stator voltages, fluxes, and rotor currents. As a consequence, the pulsations at 12th the grid frequency, which behave less significantly compared with these of the sixth, could be ignored in the system control design.

\section{A. Alternative Control Targets}

\section{System Control}

Under distorted grid voltage conditions, there are six rotorsCurrent components, i.e., $I+r d+, I+r q+, I 5$ $-r a 5-, 15-r q 5-, 17+r d 7+$, and $17+r q 7+$, that need to be regulated. Apart from controlling the dc average stator active and reactive powers, i.e., $P S O$ and $Q, S O$,as represented in (14), four more items can be controlled. For instance, the DFIG system can be designed to operate as one of the following control targets. Target I: No rotor current oscillations, i.e., no fifth- and seventh-order rotor current harmonics existing. Target II: Strictly sinusoidal stator current to ensure balanced heating and less harmonic losses in the three-phase stator windings.Target III: Removing the pulsations of six times the grid frequency in the stator output active and reactive powers simultaneously. Target IV: Constant stator output reactive power and electromagnetic torque to reduce the mechanical stress on the turbine system.

Other control targets such as eliminating the voltage distortions to get the network voltage harmonicfree, can also be identified, and further investigations on this will be reported in the near future. As shown in Fig. 1, since the $d+$-axis is aligned with the positive-sequence stator voltage in the stator voltage orientation (SVO), which means $U_{+}$

$s q+=0,(14)$ and (16) can be simplified.

Besides, according to (11), we obtain as follows:

$$
\begin{aligned}
& U^{+}{ }_{g d q+}=\mathrm{j} \omega_{1} \varphi^{+}{ }_{g d q+} \\
& U^{j-}{ }_{s d q 5-}=-j 5 \omega_{1} \varphi^{\mathrm{w}-}{ }_{g d q 5-} \\
& U^{\delta+}{ }_{\varepsilon d q 7+}=\mathrm{j} j 7 \omega_{1} \varphi^{\delta+}{ }_{s d q 7+}
\end{aligned}
$$

As a result, rotor current references can be obtained with different control targets. For Target $I$, there $\operatorname{arel}^{2-\rightarrow}{ }_{r d q 5-}=0$

$I^{\delta+*}{ }_{r d q 7+}=0$, thus, based on (7a), (7b), and (9), the fifth- and seventh-order harmonics of stator current are produced as follows:

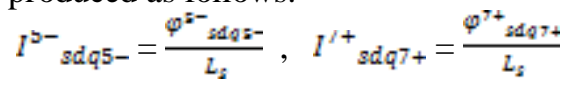

As to Target II, balanced and harmonic-free stator current means $I^{s-}{ }_{s d q 5-}=0, I^{8+}{ }_{s d q 7+}=0$. According to (7), the reference reference values of fifth- and seventh-order rotor current harmonics can be obtained as follows: 


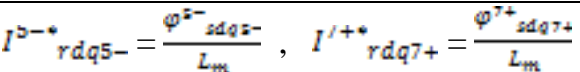

Substituting (18b) and (18c) into (20) yields

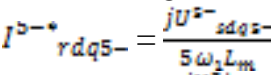

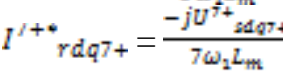

While for Target III, there are $P_{S} \cos 6=0, P_{S} \sin 6=0$,

$Q_{S} \cos 6=0$, and $Q_{S} \sin 6=0$. According to (14), the references

for the rotor current harmonic components of $-5 \omega 1$ and $7 \omega 1$ can be calculated, respectively, as follows:

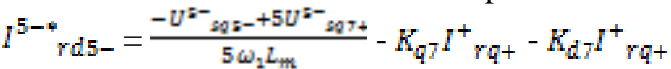

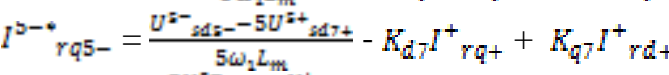

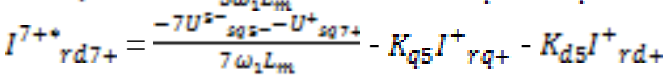

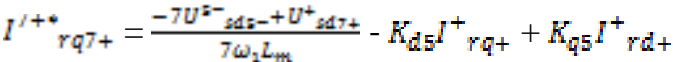

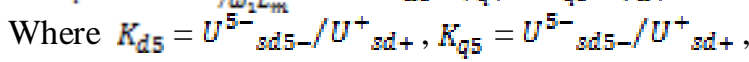

$K_{d z}=U^{7+}{ }_{s d 7+} / U^{+}{ }_{s d+}$ and $K_{q p}=U^{s+}{ }_{s q 7+} / U^{+} s d+$

As for Target $I V$, the pulsating terms at six times the grid

frequency in the instantaneous stator reactive power and electromagnetic power have to be null, viz., $P e \cos 6=$ 0, Pe $\sin 6=0, Q_{S} \cos 6=0$, and $Q_{S} \sin 6=0$. Consequently, based on (14) and (16), the references for the rotor current harmonic components of $-5 \omega 1$ and $7 \omega 1$ can be deduced as follows:

$$
\begin{aligned}
& I_{r d 5-}^{5-*}=\frac{1}{w_{2} L_{\mathrm{m}}} \lambda_{1}+\left(\frac{\mathrm{a}}{5} K_{d 5}-\frac{4}{7} K_{d 7}\right) I_{r d+}^{+}+\left(\frac{\mathrm{a}}{5} K_{q 5}-\frac{4}{7} K_{q 7}\right) I_{r q+}^{+} \\
& I_{r q 5-}^{\mathrm{b}-\infty}=\frac{1}{w_{2} L_{\mathrm{w}}} \lambda_{2}+\left(\frac{\mathrm{a}}{5} K_{q 5}+\frac{4}{7} K_{q 7}\right) I_{r d+}^{+}-\left(\frac{a}{5} K_{q 5}+\frac{4}{7} K_{d 7}\right) I_{r q+}^{+}
\end{aligned}
$$

Where $\lambda_{1}=\left(2 U^{\triangleright-}{ }_{s q 5-} / 5\right)-\left(4 U^{+}{ }_{s q 7+} / 7\right)$ and $\lambda_{2}=\left(2 U^{5-}{ }_{s d 5-} / 5\right)-\left(4 U^{+}{ }_{s d 7+} / 7\right)$

\section{B. Proposed Control Design}

Once the rotor current references are obtained, $I+r d+, I+$

$r q+, 15-r d 5-, 15-r q 5-, 17+r d 7+$, and $17+r q 7+$ are required to be regulated to follow their respective reference values precisely and rapidly. Good performance of the control strategy relies on the accurate decoupling of the $d$-and $q$-axis components and removal of the impact of the distorted network voltage.

In this section, a new control design is developed. The control system consists of a standard PI controller and a generalized ac integrator [19], which is referred as resonant (R) controller in this paper, and tuned at sixth the grid voltage frequency. The control scheme is implemented in the $(d q)+$ reference frame without the need for sequential-component decomposition of voltages and currents. According to (7a) and (7b), it can be seen that under distorted grid voltage conditions, the voltage, current, and flux in the $(d q)+$ reference frame all contain both dc values of the positive sequence of fundamental component and ac terms of the harmonic components of $-5 \omega 1$ and $7 \omega 1$ pulsating at the frequencies of $\pm 6 \omega 1$. It is worth noting that the generalized ac integrator $(\mathrm{R})$ is a double-side integrator [11], [19], which means a resonant part tuned at the angular frequency of $6 \omega 1$ is not only able to nullify the error for the positive sequence at the frequency of $6 \omega 1$ but also for the negative at $-6 \omega 1$. Consequently, similar to the zero error of dc components regulatedby the standard PI controller, the error to the ac signal with the frequencies of $\pm 6 \omega 1$ could be sufficiently eliminated by the application of a resonant regulator tuned at $6 \omega 1$ in the current controller. Therefore, a PI plus R (PI-R) rotor current controller in the $(d q)+$ reference frame can be developed for directly regulating both the positive sequence of the fundamental component and the harmonic components of $-5 \omega 1$ and $7 \omega 1$, as shown in Fig. 3. Based on (5) and (10), a DFIG system under distorted grid voltage conditions can be represented in the $(d q)+$ reference frame as follow:

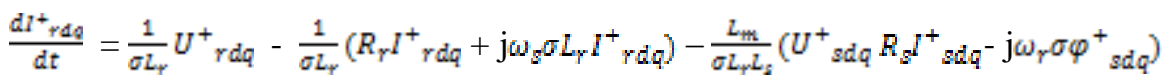




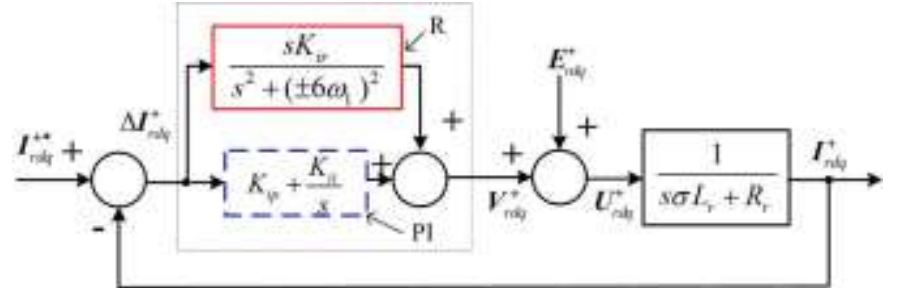

Fig. 3. Rotor current control diagram based on the developed PI-R regulator.

Where $\boldsymbol{U}_{+} r d q$ is referred to the rotor control voltage produced by the PI-R controller, which is designed as follows:

Where

$$
U^{+}{ }_{r d q}=\sigma L_{Y} V^{+}{ }_{r d q}+E_{r d q}^{+}
$$

$$
\begin{aligned}
V_{r d q}^{+}=\frac{d}{d t} I_{r d q}^{+} & =C_{P I-H}(\mathrm{~s})\left(I_{r d q}^{+*}-I_{r d q}^{+}\right) \\
& =\left[K_{i p}+\frac{K_{i I}}{s}+\frac{s K_{1 r}}{s^{2}+\left( \pm 6 w_{2}\right)^{2}}\right]\left(I^{+*}{ }_{r d q}-I^{+}{ }_{r d q}\right)
\end{aligned}
$$

And

$$
E_{r d q}^{+}=\left(R_{r} I_{r d q}^{+}+\mathrm{j} \omega_{g} \sigma L_{y} I_{r d q}^{+}\right)+L_{m}\left(U^{+}{ }_{s d q}-R_{g} I_{s d q}^{+} \quad \quad \mathrm{j} \omega_{r} \varphi_{g d q}^{+}\right) / L_{g}
$$

is defined as the equivalent rotor back electromagnetic force acting as a disturbance to the PI-R controller, and Kip , Kii , and Kir are the proportional, integral, and resonant parameters,respectively, which can be determined based on the Naslin polynomial [11], [20].

According to Fig. 3, the closed-loop transfer function of the Rotor current controller can be obtained as follows:

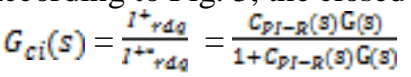

$$
\begin{aligned}
& =\frac{N_{d}(s)}{s\left[s^{2}+\left( \pm j 6 w_{2}\right)^{2}\right)\left(s \sigma L_{1}+R_{f}\right)+N_{d}(s)} \\
& N_{c}(s)=K_{i p}\left[s^{a}+s\left( \pm j 6 \omega_{1}\right)^{2}\right]+K_{\mathrm{ii}}\left[s^{2}+\left( \pm j 6 \omega_{1}\right)^{2}\right]+s K_{\mathrm{ir}}
\end{aligned}
$$

Substituting $S= \pm j 6 \omega_{1}$ into (26) results in

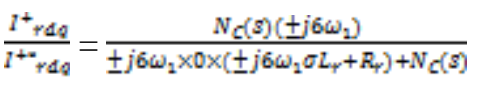

$$
\begin{aligned}
& =1
\end{aligned}
$$

This implies that the developed PI-R controller can provide

zero steady-state error for the $\pm 6 \omega 1$ ac signal regardless of the DFIG's parameters $\sigma L r$ and $R r$. However, from Fig. 3, the transfer function of the $\boldsymbol{E}+r d q$ to the rotor current can be derived as follows:

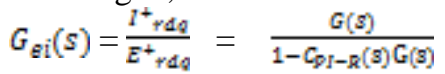

$$
\begin{aligned}
& =\frac{g\left(g^{2}+\left( \pm j 6 w_{2}\right)^{2}\right)}{s\left[\left(g^{2}+\left( \pm j 6 w_{2}\right)^{2}\right)\left(s \sigma L_{1}+R_{4}\right)-N_{(}(s)\right.}
\end{aligned}
$$

Substituting $S= \pm j 6 \omega_{1}$ into (28) yields

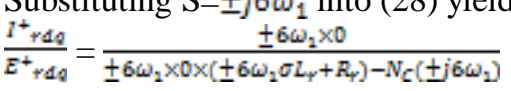

$$
\begin{aligned}
& =0
\end{aligned}
$$

This indicates that the introducing of the $\mathrm{R}$ regulator has little impact on the positive-sequence rotor current control and the proposed PI-R controller gets rid of the effect of $\boldsymbol{E}+r d q$ upon the rotor current control loop and the characteristic is hardly affected by the system parameters $\sigma L r$ and $R r$. Based on the analytical results represented in (27) and (29), the effectiveness and robustness of the proposed control scheme have been validated theoretically. As shown in (25), Kip plays the same role as for that in the standard PI regulator, which basically determines the system dynamics in terms of bandwidth, phase, and gain margin . While the resonant regulator with Kir provides infinite gain for the ac components at the frequencies of $\pm 6 \omega 1$. As a result, the PI-R controller is only relatively sensitive to the grid's angular frequency $\omega 1$, which can be accurately gained via phase-lock loop (PLL). Besides, in order to reduce the sensitivity of the $\mathrm{R}$ regulator toward slight frequency variations in a typical wind farm connected grid, a component with cutoff frequency of $\omega c$ can be inserted into the resonant part to increase its frequency bandwidth [9], [11]. Consequently, the PI-R controller in thepractical control system is given as follows 


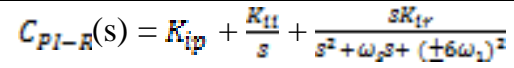

: As a result, according to (2a) and (25), the required rotor control voltage can be transformed into the $(\alpha \beta) r$ reference frame rotating at the angular speed of $\omega r$ as follows:

$$
U^{r}{ }_{\gamma \times \beta}=U^{+}{ }_{\gamma \times \beta} e^{J\left(\theta_{2}-\theta_{f \gamma}\right)}
$$

Thus, space vector modulation (SVM) module can be used to generate the required switching voltage vectors and their respective duration times.

\section{Sequential Decomposition of Network Voltage}

As represented in (21)-(23), in order to derive the rotor current references, accurate extraction of the positive-sequence component of the fundamental term and the harmonic components of $-5 \omega 1$ and $7 \omega 1$ from the distorted grid voltage is necessitated. Different methods can be used to estimate the sequential components of the polluted grid voltage, this paper introduces a new structure with the multiple complex-coefficient filter (MCCF) [21], so as to achieve the accurate and rapid extraction for the specified sequences, viz., $U_{+} s d_{+}, L_{-}-$ $s d 5-, U 5-s q 5-, U 7+s d 7+$, and $U 7+s q 7+$. The MCCF-based structure is shown in Fig. 4(a), where $\boldsymbol{U} \alpha \beta$ is the original grid voltage in the stationary $\alpha \beta$ reference frame and used as the input of MCCF, and $\sim S \alpha \beta+$, $\sim \boldsymbol{U} s \alpha \beta 5-$, and $\sim \boldsymbol{U} s \alpha \beta 7+$ are the estimated fundamental and harmonic sequence components ,respectively where $\omega c 0$ is cutoff frequency and set to an optimum damping ratio of $0.707 \omega 1$. Once the fundamental- and harmonic-sequence components are estimated in the stationary $\alpha \beta$ reference frame, the PLL can be used to track the frequency and angular information of the fundamental voltage, as shown in Fig. 4(b). As a consequence, the estimated as

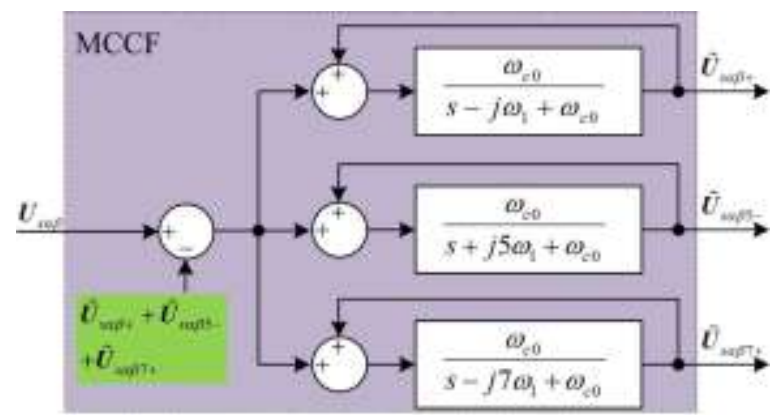

(a)

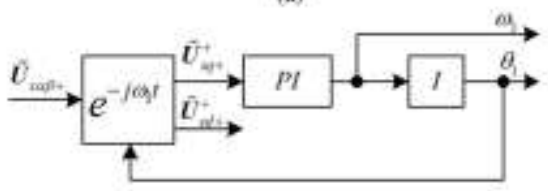

(b)

Fig. 4. (a) MCCF structure. (b) Standard PLL.

According to Fig. 4(a), the mathematical model of the MCCF can be obtained as follows:

$$
\begin{aligned}
& \widetilde{U}_{s \alpha \beta+}=\frac{w_{s 0}}{s-j w_{1}+\omega_{c o}}\left[U_{s \alpha \beta}-\widetilde{U}_{s \alpha \beta 5-}-\widetilde{U}_{s \alpha \beta 7+}\right] \\
& \widetilde{U}_{s \alpha \beta 5-}=\frac{\omega_{\omega 0}}{s+j 5 \omega_{1}+\omega_{s c}}\left[U_{s \alpha \beta}-\widetilde{U}_{s \alpha \beta+}-\widetilde{U}_{s \alpha \beta 7+}\right]
\end{aligned}
$$

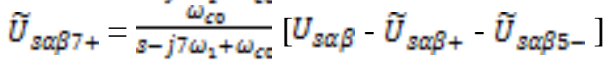

$\sim \boldsymbol{U} s \alpha \beta+, \tilde{U} s \alpha \beta 5-$, and $\sim \boldsymbol{U} S \alpha \beta 7+$ can be transformed into their respective synchronous reference frames and the required $U_{+} s d+, L 5-s d 5-, L 5-s q 5-, U 7+s d 7+$, and $U 7+s q 7+$ are obtained accurately.

\section{System Implementation}

Based on the developed control strategies, an improved controlscheme for the DFIG system under distorted grid voltage conditions is shown in Fig. 5. The measured three-phase rotorcurrents are directly transformed into the $(d q)+$ reference frame, which results in $\pm 6 \omega 1$ ac signal supimposed on a dc signal according to (4b). However, based on the MCCF structure, the fundamental- and harmonic-sequence components of grid voltage are estimated, respectively. Consequently, the rotor current references, viz., $I+* r d+$, $I+* r q+, 15-* r d 5-, 15-* r q 5-, 17+* r d 7+$, and $17+* r q 7+$, are calculated with different control targets. As in (21)-(23), the rotor current references are all dc signals separated in the $(d q)+,(d q) 5-$, and $(d q) 7+$ reference 
frames. Therefore, the harmonic rotor current references have to be transformed to the $(d q)+$ reference frame. According to (7b), the rotor current references in the $(d q)+$ reference frame are given as follows:
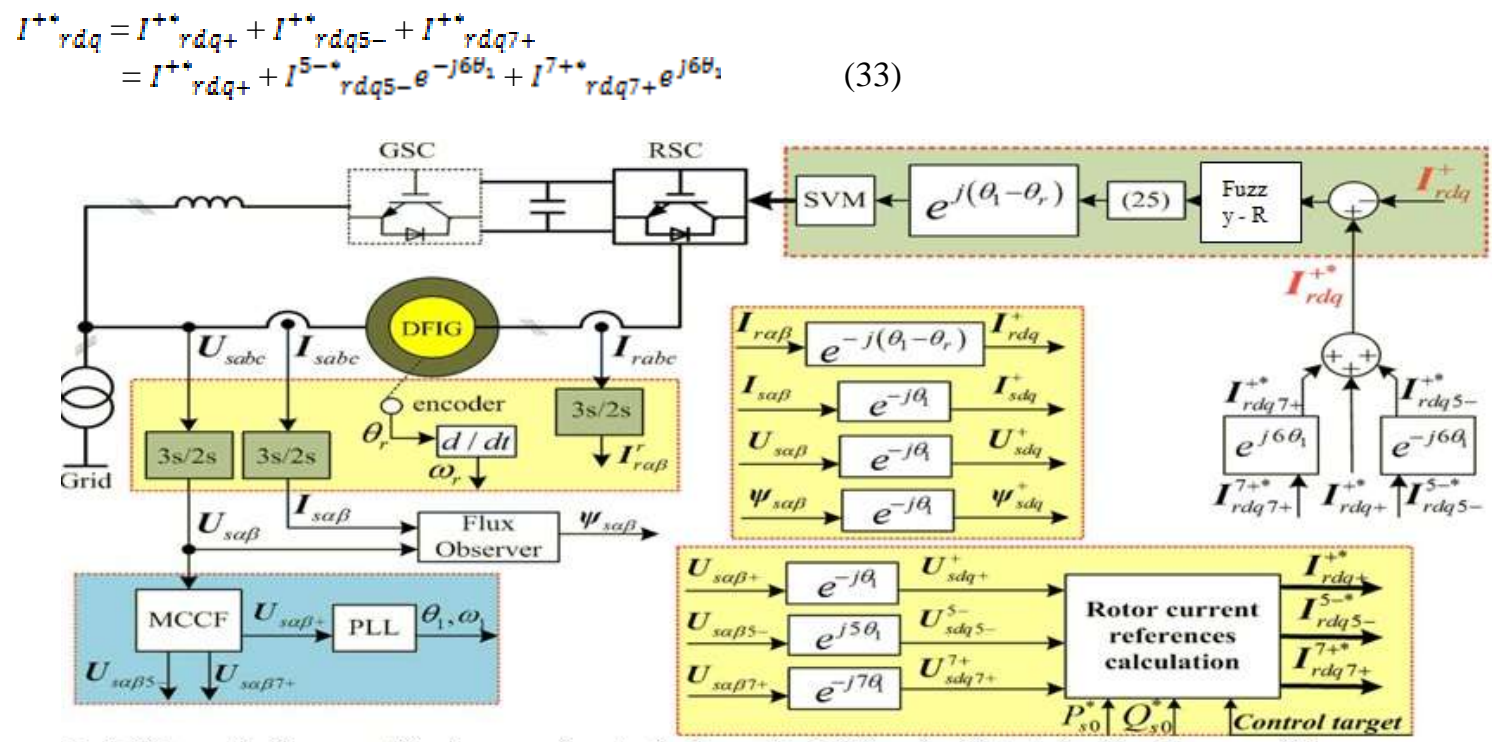

Fig. 5. Schematic diagram of the improved control scheme for DFIG under distorted grid voltage conditions.

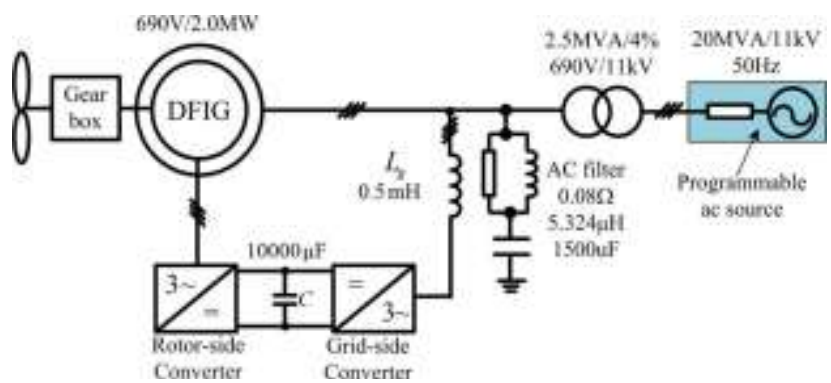

Fig. 6. Scheme of the simulated system.

IV. Simulation Results

Simulations of the proposed control strategy for a DFIG based wind power generation system were carried out using MATLAB/Simulink, and Fig. 6 shows the scheme of the implemented system. Discrete models were used with a simulation time step of $5 \mu \mathrm{s}$. The DFIG is rated at $2 \mathrm{MW}$ with its parameters given in the Appendix. The nominal converter dc link voltage was set at $1200 \mathrm{~V}$. The grid-side converter has to maintain a constant dc-link voltage, and it is controlled by a method similar to the dc voltage controller in a pulsewidth modulation (PWM) grid-connected voltage-source converter [18], which is not included here. During simulations, a sampling frequency of $10 \mathrm{kHzwas}$ used for the proposed control strategy. Due to the use of an asymmetric SVM technique, a $2.5 \mathrm{kHz}$ converter switching frequency was set. As shown in Fig. 6, a highfrequency ac filter is connected to the stator side to absorb the switching harmonics generated by the two converters. The filter is a single tuned filter with inductance and resistance connected in parallel instead of series, which results in a wideband filter having an impedance at high frequencies limited by the resistance [22]. A programmable ac source was used to generate fifth and seventh grid voltage harmonics, which were set to $4 \%$ and 3\% respectively, throughout the steady-state simulation studies. In a practical system, voltages and currents are sampled at the beginning of each sampling period. The required rotor control voltage for the sampling period is, then, calculated and passed to the SVM module. Inevitably, there is a time delay between the instant sampling and SVM modulator's receiving the required rotor control voltage and updating its register values. Rotor voltage calculation of the proposed control strategy is relatively simple, and the time delay should be pretty small. Nevertheless, the calculated output rotor voltage is delayed by $100 \mu \mathrm{s}$ (one sampling period) to closely represent a practical DFIG control system. During the simulation, the grid-side converter is enabled first, so that the converter dc-link voltage is regulated. The generator is, then, excited by rotor-side converter with the rotor rotating at a fixed speed till the stator voltage matches with the network voltage, such that the DFIG system is switched into grid-connected operation. This starting process is not shown in the following results. For the first instance, the DFIG's rotor speed was fixed at 0.8 p.u. with the synchronous speed being 1.0 p.u., since the large inertia of wind turbines leads to slow changes of rotor speed. Fig. 7 compares the simulation results by 
Fuzzy Logic Control Of DFIG To Eliminate Unbalances In Weak Grid System the conventional vector control [1] and the proposed control strategy under distorted grid voltage conditions. In the conventional control

(7a)

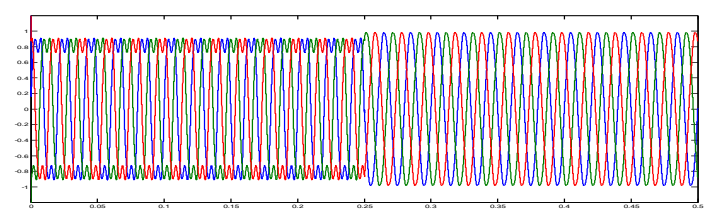

(7b)

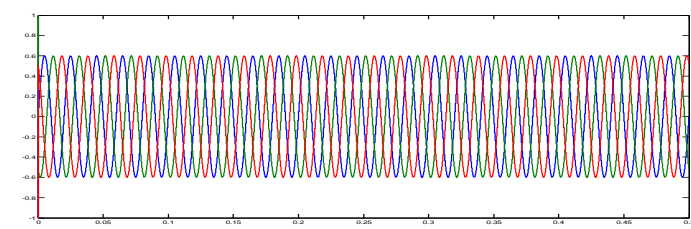

(7c)

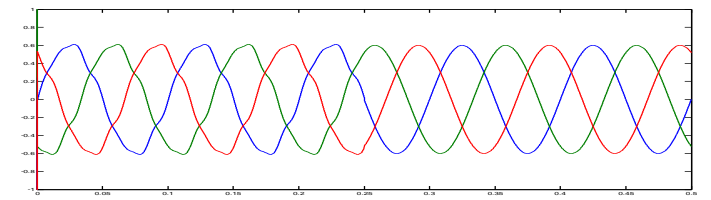

(7d)

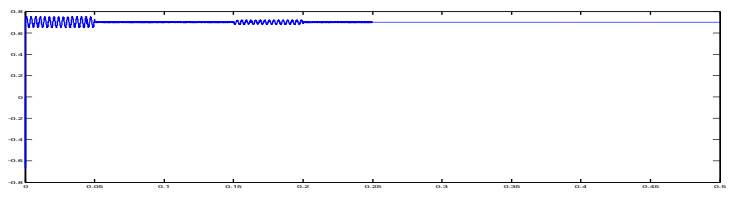

$(7 e)$

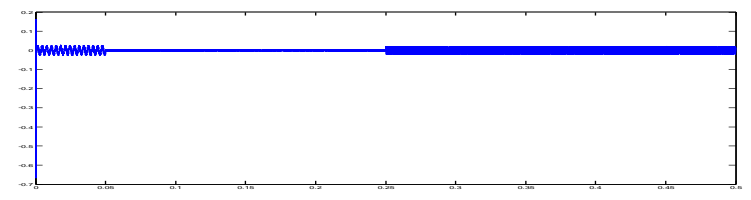

(7f)

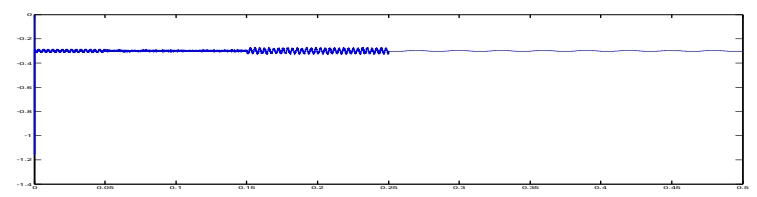

$(7 \mathrm{~g})$

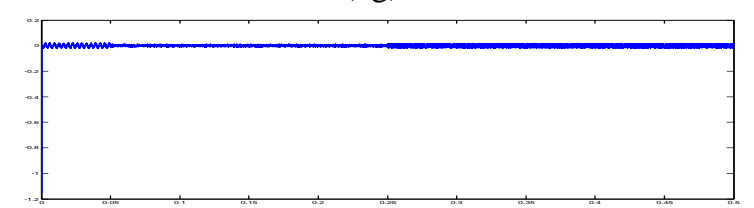

(7h)

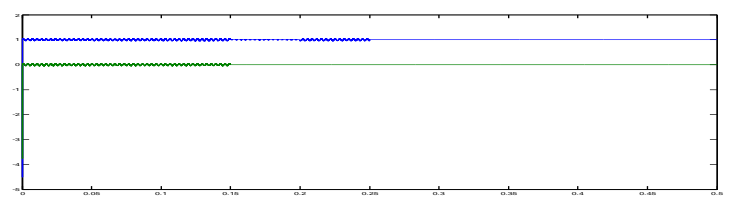

(7i) 


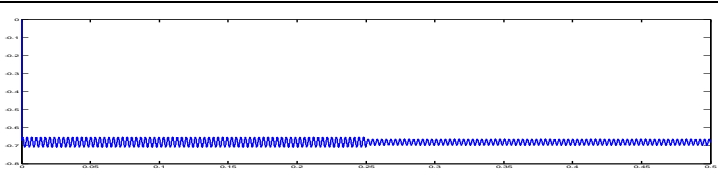

$(7 \mathrm{j})$

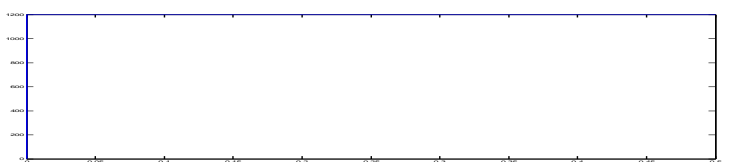

Fig. 7. Simulated results with different control targets. (a) Three-phase statorvoltages (in p.u.). (b) Three-phase stator currents (in p.u.). (c) Three-phase rotor currents (in p.u.). (d) $d+$-axis rotor current reference and response (in p.u.). (e) $d$-axis rotor current error (in p.u.). (f) $q+-$-axis rotor current reference and response (in p.u.). (g) $q+$ -axis rotor current error (in p.u.). (h) Stator output active and reactive powers (in p.u.). (i) DFIG's electromagnetic torque (in p.u.). (j) DC-link voltage (in V).

system, a single PI rotor current controller in the synchronous reference frame was used and stator voltage harmonics was not taken into account. The average stator active and reactive powers

TABLE I

\section{COMPARISON RESULTS OF DIFFERENT CONTROL TARGETS}

\begin{tabular}{|c|c|c|c|c|c|}
\hline & 1 & II & III & IV & Conventional \\
\hline I $5^{\text {l }}$ harmouics (\%) & 0.50 & 0,40 & 3.13 & 2.48 & 4.87 \\
\hline I. $7^{\mathrm{t}}$ harmonics (\%) & 0.20 & 0.23 & 4.07 & 1.96 & 385 \\
\hline$I_{t} 29^{\mathrm{h}}$ harmonics $(\%)$ & 0.36 & 0.52 & 2.58 & 2.08 & 4.18 \\
\hline I.31" harmonics (\%) & 0.19 & 0.32 & 3,90 & 1.93 & 3.60 \\
\hline Ps pulsation (\%) & \pm 4.55 & \pm 4.61 & \pm 0.51 & \pm 496 & $\pm 4,35$ \\
\hline$Q_{\text {. pulsation }(\%)}$ & \pm 4.87 & \pm 4.89 & \pm 0.47 & \pm 0.45 & \pm 5.08 \\
\hline$T_{\text {e pulsation (\%) }}$ & \pm 0.68 & \pm 0.82 & $\$ 4.02$ & $\pm 0,35$ & $\$ 5.69$ \\
\hline$V_{\text {w }}$ pulsation (V) & \pm 37 & \pm 39 & \pm 42 & \pm 4.1 & \pm 43 \\
\hline
\end{tabular}

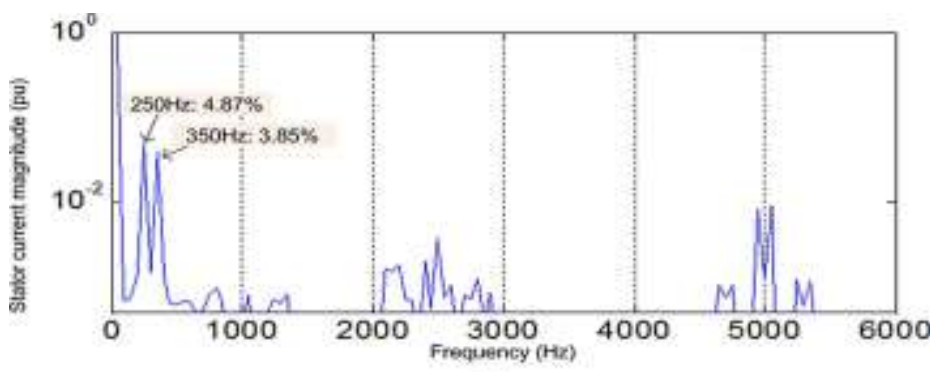

(a)

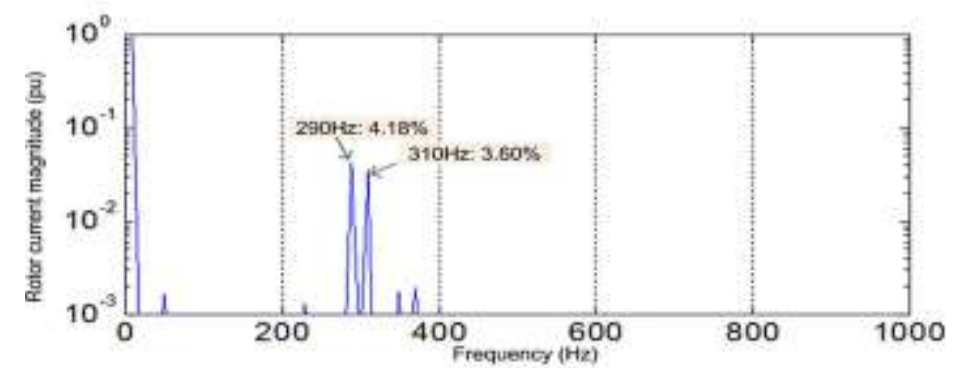

(b)

Fig. 8. Harmonic spectra. (a) Stator current spectrum (relative to the fundamental $50 \mathrm{~Hz}$ stator current). (b)Rotor current spectrum (relative to the fundamental $10 \mathrm{~Hz}$ rotor current). were set at $2 \mathrm{MW}$ and $0 \mathrm{Var}$, respectively Within the period of $0-0.05 \mathrm{~s}$, the conventional control without grid distortion considered was employed and the resonant part in the PI-R rotor current controller was disabled. At the instant of $0.05 \mathrm{~s}$, the resonant regulator was enabled with Target I selected. Afterward, the system control target was switched to Target II at $0.1 \mathrm{~s}$, Target III at $0.15 \mathrm{~s}$, and Target IV at $0.2 \mathrm{~s}$, respectively. As shown from Fig. 7(d)- $(\mathrm{g})$, with the conventional control within the first $0.05 \mathrm{~s}$, the standard PI rotor current regulator failed to control the harmonic rotor currents in the positive synchronous reference 
frame, as a consequence, the three-phase stator currents were badly distorted, as shown in Fig. 7(b). In addition, there existed significant $300 \mathrm{~Hz}$ pulsations in the instantaneous stator active and reactive powers, and the electromagnetic torque. The rotor currents contained both $10 \mathrm{~Hz}$ fundamental component, i.e., $50-40 \mathrm{~Hz}$, and the harmonic components of $290 \mathrm{~Hz}(250+40 \mathrm{~Hz})$ and $310 \mathrm{~Hz}(350-40 \mathrm{~Hz})$, respectively. For clear illustrations, Fig. 8 shows the harmonic spectra of the stator and rotor currents during $0-0.05 \mathrm{~s}$. Once the developed PI-R rotor current regulator was enabled at $0.05 \mathrm{~s}$, as can be seen fromFig. 7(d)-(g), both the positive sequence of the fundamentaland the harmonic-sequence rotor current components were controlled precisely and rapidly. In particular, the tracking of the harmonic rotor currents to their respective reference values was quite satisfactory during the switching among the different control targets.

For the purpose of clear comparisons, the measured fifthand seventh-order stator current harmonics, rotor current ratios of $290 \mathrm{~Hz}$ (29th) and $310 \mathrm{~Hz}$ (31st) harmonics with respect to the $10 \mathrm{~Hz}$ fundamental component, $300 \mathrm{~Hz}$ peak-to-peak pulsations of the stator output active and reactive powers, DFIG's electromagnetic torque and converter's dc-link voltage are summarized and compared in Table I with various control targets. It can be apparently seen from Fig. 7 and Table I that using the proposed control strategies and the developed PI-R control design, the predefined control targets have been fully achieved, respectively. Moreover, Target I not only minimized the 29thand 31st-order harmonics of rotor currents, but also gave significant attenuations in the stator current harmonics and the $300 \mathrm{~Hz}$ pulsations in the generator's electromagnetic torque. Similarly, Target II attenuated the harmonic components of stator and rotor currents, and the torque oscillations simultaneously.

Since the exchange of active power between the DFIG rotor and the rotor-side converter contains 300 $\mathrm{Hz}$ oscillation, the dc-link voltage also oscillated at $300 \mathrm{~Hz}$ with peak-to-peak amplitude of around $8 \mathrm{~V}$. The impact of such oscillation on the system operation is found to be negligible as both the rotor current and the current for the grid-side converter (not shown in this paper due to space limitation) are controlled precisely. If required, the dc capacitance could be increased to reduce such oscillation.

Similar tests with various rotor speeds and different combinations of the stator output active and reactive powers were also carried out and the system performance behaved analogically to those shown in Figs. 7 and 8, and Table I.
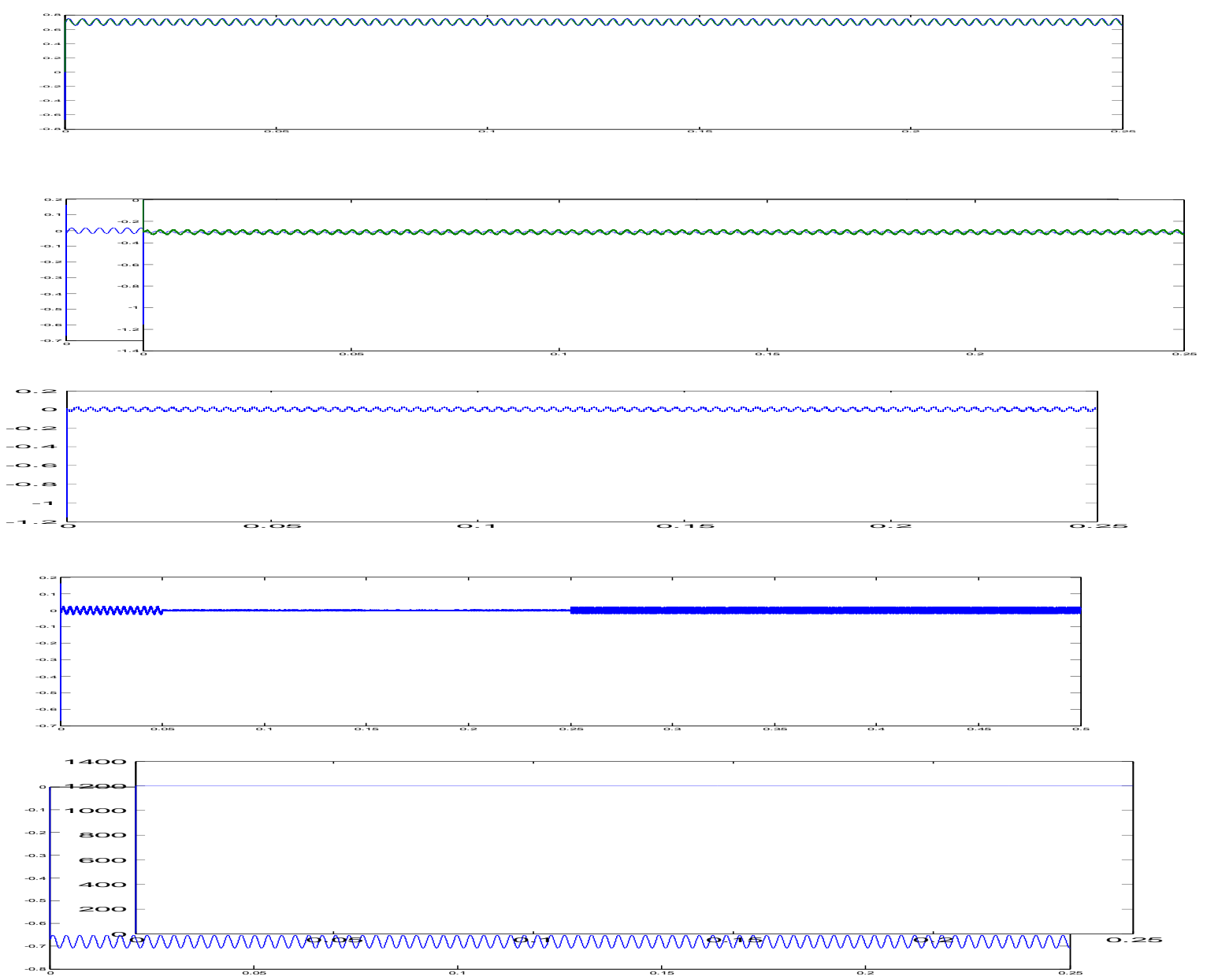

Fig. 9. Simulated results with mutual inductance, and stator and rotor resistances used in the controller having various errors. (a) $d+$-axis rotor current reference and response (in p.u.). (b) $d+$-axis rotor current error (in 
p.u.). (c) $q+-$ axis rotor current reference and response (in p.u.). (d) $q+$-axis rotor current error (in p.u.). (e) Stator output active and reactive powers (in p.u.). (f) DFIG's electromagnetic torque (in p.u.). (g) DC-link voltage (in v)

For the practical systems, the selection of control target will highly depend on the design of wind turbines and the operational requirement of network. While, by adopting one of the control targets aforementioned and the proposed current control scheme, system operation, and performance can be The results are shown in Fig. 10 with generator speed being 1.2 p.u. and harmonic distortions occurring between 0.1 and 0.2 s. In order to demonstrate the effectiveness of the proposed PI-R
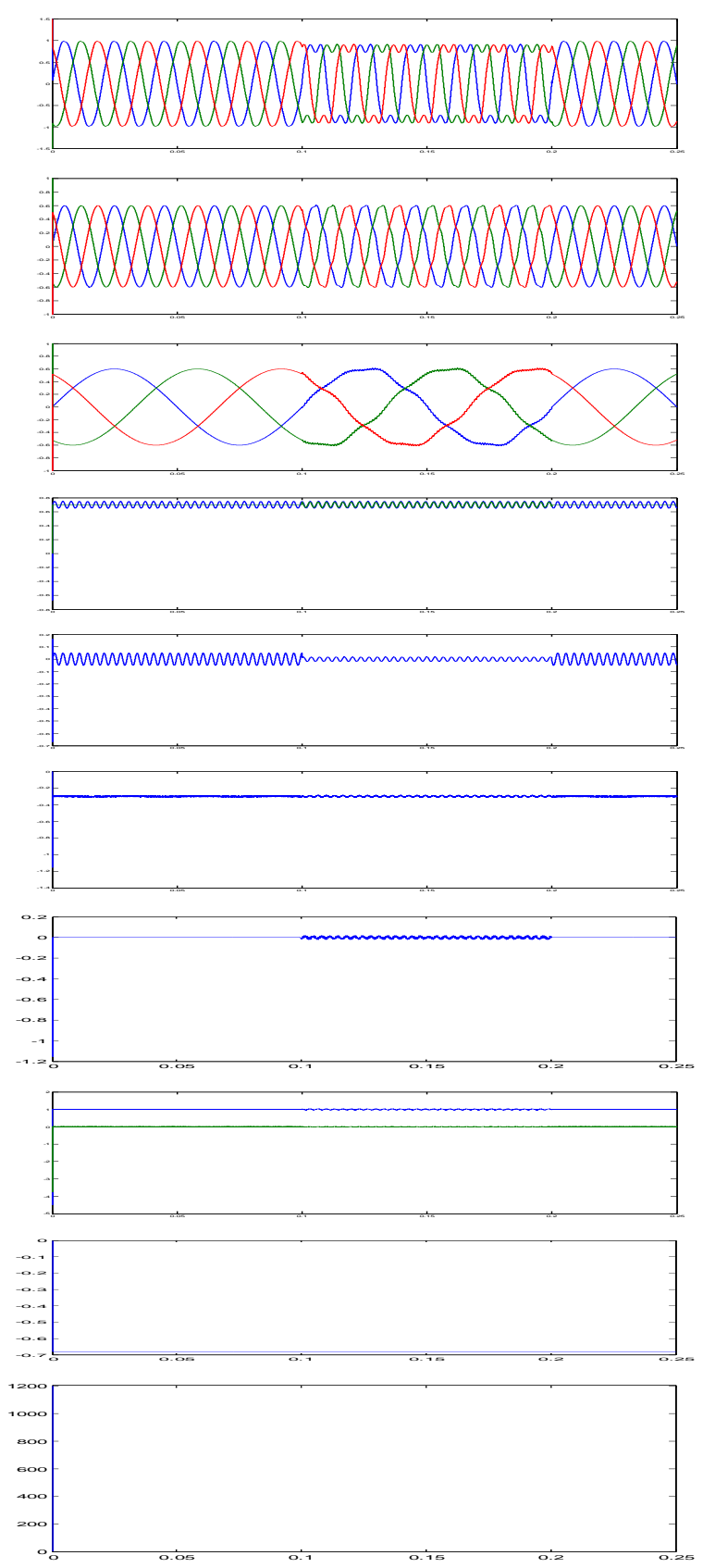

Fig. 10.(1) Simulated results with Target III during transient grid voltage distortions of 5\% fifth and seventh harmonic components. (a) Three-phase stator voltages (in p.u.). (b) Three-phase stator currents (in p.u.). (c) Three-phase rotor currents (in p.u.). (d) $d+$-axis rotor current reference and response (in p.u.). (e) $d+-$ axis rotor current error (in p.u.). (f) $q+$-axis rotor current reference and response (in p.u.). (g) $q+$-axis rotor current error (in p.u.). (h) Stator output active and reactive powers (in p.u.). (i) DFIG's electromagnetic torque (in p.u.). (j) DC-link voltage (in V). (A) Conventional control with standard PI [1]. (B) Proposed control design. 
7.
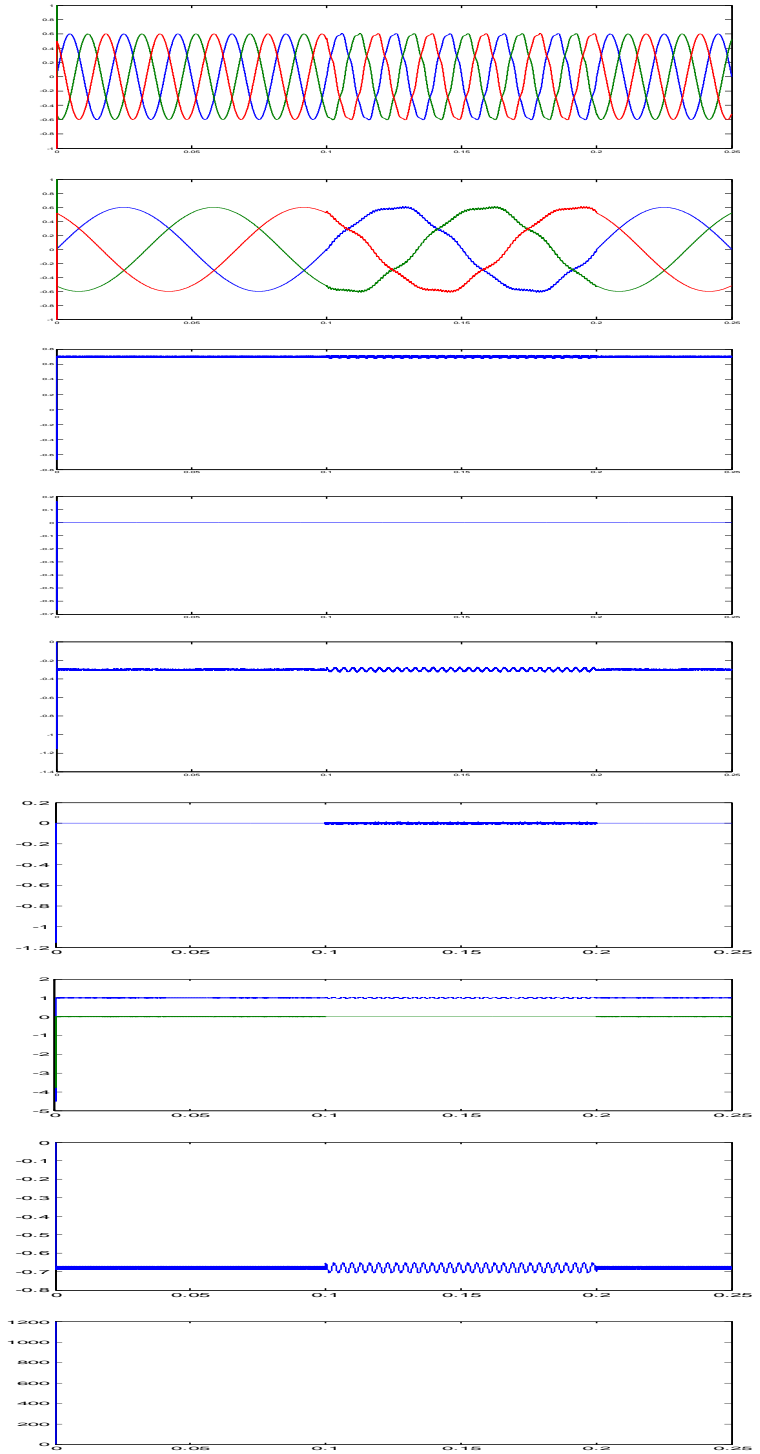

Fig. 10(2). Simulated results with Target III during transient grid voltage distortions of 5\% fifth and seventh harmonic components. (a) Three-phase stator voltages (in p.u.). (b) Three-phase stator currents (in p.u.). (c) Three- phase rotor currents (in p.u.). (d) $d+$-axis rotor current reference and response (in p.u.). (e) $d+$-axis rotor current error (in p.u.). (f) $q+$-axis rotor current reference and response (in p.u.). (g) $q+-$ axis rotor current error (in p.u.). (h) Stator output active and reactive powers (in p.u.). (i) DFIG's electromagnetic torque (in p.u.). (j) DC-link voltage (in V).

As a result, it can be seen, by comparing Fig. 10(a) and (b), thatwith the proposed control system, the operation of the generationsystem during such transient voltage harmonic distortion was much smoother with the oscillations in both stator reactive power and electromagnetic toque removed completely.

After the voltage distortions cleared, the $\mathrm{R}$ regulator controlled the harmonic rotor current components to be null of itself and the system was back to the normal operation. System responses of the proposed control strategy with variations of generator's torque and speed were also investigated and the results are shown in Fig. 11. The generator speed was step changed from 1.2 to 0.8 p.u. at $0.1 \mathrm{~s}$. According to the maximum power point tracking curve, the DFIG's stator active power and electromagnetic torque were changed from 1 to 0.25 p.u., and from -0.68 to -0.16 p.u., respectively. The stator output reactive power was kept at 0.35

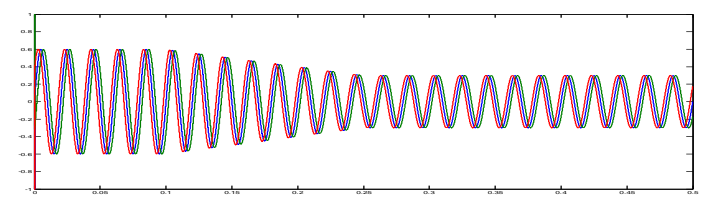



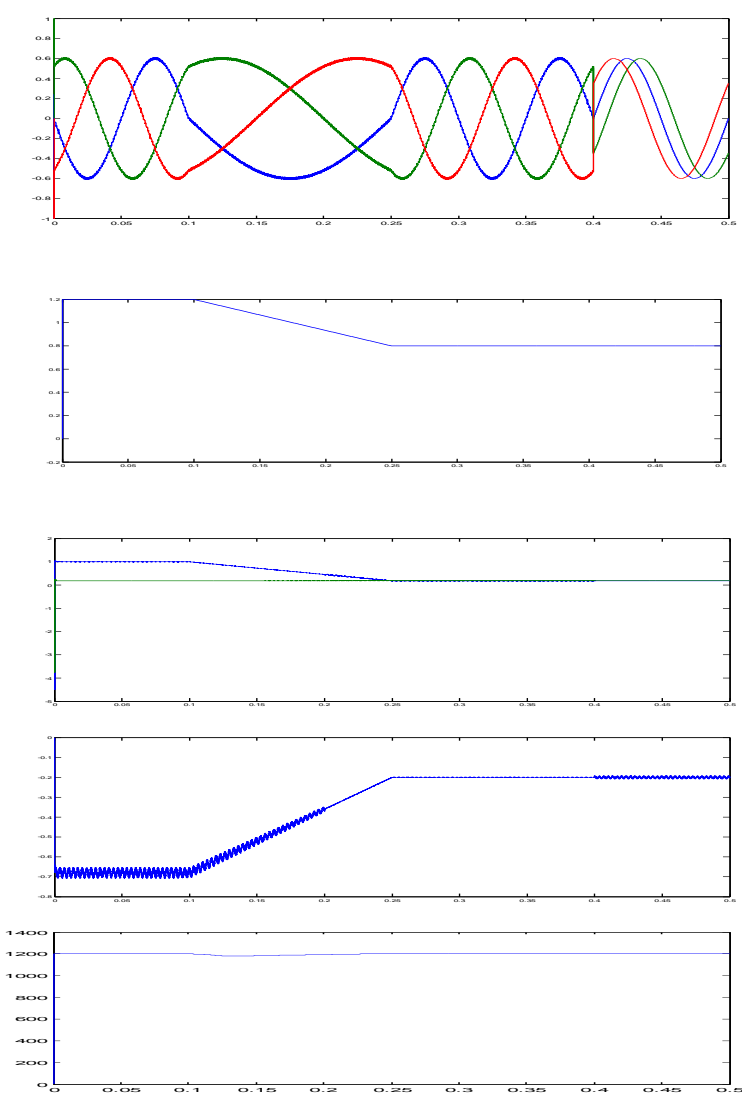

Fig. 11. Simulated results with torque and generator speed variations. (a)Three-phase stator currents (in p.u.). (b) Three-phase rotor currents (in p.u.). (c) Generator speed (in p.u.). (d) Stator output active and reactive powers (in p.u.). (e) Electromagnetic torque (in p.u.). (f) DC-link voltage (in V).

\section{PARAMETERS OF THE SIMULATED DFIG}

TABLE II

\begin{tabular}{|l|l|}
\hline Rated power & $2 \mathrm{MW}$ \\
\hline Stator voltage & $690 \mathrm{~V}$ \\
\hline Stator/rotor tums ratio & 0.33 \\
\hline$R_{s}$ & $0.0108 \mathrm{pu}$ \\
\hline$R_{r}$ & $0.0121 \mathrm{pu}$ \\
\hline$L_{w}$ & $3.362 \mathrm{pu}$ \\
\hline$L_{o s}$ & $0.102 \mathrm{pu}$ \\
\hline$L_{o r}$ & $0.11 \mathrm{pu}$ \\
\hline Number of pole pairs & 2 \\
\hline Lumped inertia constant & $0.2 \mathrm{~s}$ \\
\hline
\end{tabular}

p.u. (leading). The stator voltage had $4 \%$ fifth-order and 3\% seventh-order harmonic distortions.

Target $I I I$ was initially chosen, but switched to Target $I V$ at $0.2 \mathrm{~s}$. The lumped inertia constant of the generation system was set to a smaller value of $0.2 \mathrm{~s}$ in this study for a better illustration. From Fig. 11(d), it can be seen that within the period of $0-0.2 \mathrm{~s}$, the stator output active and reactive powers had no $300 \mathrm{~Hz}$ pulsations at all, although the stator voltage was distorted with fifth and seventh harmonics. Once the controller was switched to Target $I V$ at $0.2 \mathrm{~s}$, the $300 \mathrm{~Hz}$ oscillations in both the electromagnetic torque and the stator reactive power were eliminated quickly. Apparently, Fig. 11 indicates that the system performance during the variations of the DFIG's torque and speed is quite satisfactory. 


\section{Conclusion}

This paper has presented an analysis and improved control of a wind-turbine-driven DFIG operating under distorted grid voltage conditions. Simulated studies on a 2 MW DFIG wind power generation system are carried out to validate the proposed control strategies. As a result, the following conclusions can be drawn.

1) When the grid voltage is harmonically distorted, viz., taking the positive sequence of the fundamental and the harmonics at the frequencies of $-5 \omega 1$ and $7 \omega 1$ into account, the DFIG's electromagnetic torque and instantaneous stator active and reactive powers have been fully defined, which indicates that significant oscillations at six times the grid frequency do exist and should be attached importance to.

2) Methods for improving system responses of wind-turbine driven DFIG systems under distorted grid voltage conditions are identified. Alternative control targets are capable of keeping sinusoidal the three-phase stator currents or rotor currents, or removing pulsations in both stator active and reactive powers, or in the generator's electromagnetic torque and stator reactive power. In contrast, the conventional vector control scheme of DFIG results in significant pulsations of the stator active/reactive powers and electromagnetic torque, and excessive harmonics in the stator/rotor currents, even with a small stator voltage distortion.

3) A rotor current scheme that is implemented in the positive synchronous reference frame is developed. The control scheme consists of a PI regulator and a harmonic resonant compensator tuned at six times the grid frequency. As a result, the fundamental and the fifth- and seventhorder components of rotor currents are directly regulated by the PI-R controller without involving any sequential component decompositions. Consequently, the proposed respective control targets can be fully accomplished.

\section{References}

[1] R. Pena, J. C. Clare, and G. M. Asher, "Doubly fed induction generator using back-to-back PWM converters and its application to variable-speed wind-energy generation," IEE Proc. Electric Power Appl., vol. 143, no. 3, pp. 231-241, May 1996.

[2] S. Muller, M. Deicke, and R. W. De Doncker, "Doubly fed induction generator systems for wind turbines," IEEE Ind. Appl. Mag., vol. 8, no. 3, pp. 26-33, May/Jun. 2002.

[3] J. B. Hu and Y. K. He, "Dynamic modeling and robust current control ofwind-turbine used DFIG during AC voltage dip," J.Zhejiang Univ. SCI.A, vol. 7, no. 10, pp. 1757-1764, Oct. 2006.

[4] J. Morrent and S. W. H. de Haan, "Ride-through of wind turbines with doubly-fed induction generator during a voltage dip," IEEE Trans. Energy Convers., vol. 20, no. 2, pp. 435-441, Jun. 2005.

[5] S. Seman, J. Niiranen, and A. Arkkio, "Ride-through analysis of doubly ed induction wind-power generator under unsymmetrical network disturbance," IEEE Trans. Power Syst., vol. 21, no. 4, pp. 1782-1789, Nov. 2006.

[6] L. Xu and Y.Wang, "Dynamic modeling and control of DFIG based wind turbines under unbalanced network conditions," IEEE Trans. Power Syst., vol. 22, no. 1, pp. 314-323, Feb. 2007.

[7] L. Xu, "Coordinated control of DFIG's rotor and grid side converters during network unbalance," IEEE Trans. Power Electron., vol. 23, no. 3, pp. 1041-1049, May 2008.

[8] L. Xu, "Enhanced control and operation of DFIG-based wind farms during network unbalance," IEEE Trans. Energy Convers., vol. 23, no. 4, pp. 1073-1081, Dec. 2008.

[9] J. Hu, Y. He, L. Xu, and B. W. Williams, "Improved control of DFIG systems during network unbalance using PI-R current regulators," IEEE Trans. Ind. Electron., vol. 56, no. 2, pp. 439-459, Feb. 2009.

[10] J. Hu and Y. He, "Modeling and enhanced control of DFIG under unbalanced grid voltage conditions," Electric Power Syst. Res., vol. 79, no. 2, pp. 273-281, Feb. 2009.

[11] J. Hu and Y. He, "Reinforced control and operation of DFIG-based windpower- generation system under unbalanced grid voltage conditions," IEEE Trans. Energy Convers., vol. 24, no. 4, pp. 905-915, Dec. 2009.

[12] Y. Zhou, P. Bauer, J. A. Ferreira, and J. Pierik, "Operation of gridconnected DFIG under unbalanced grid voltage conditions," IEEE Trans. Energy Convers., vol. 24, no. 1, pp. 240-246, Mar. 2009.

[13] IEEE Recommended Practices and Requirements for Harmonic Control in Electrical Power Systems, IEEE Standard 519-1992, 1993.

[14] Managing Harmonics-A Guide to Ena Engineering Recommendation G5/4-1. London, U.K.: The Gambica Association Limited, 2005.

[15] G. K. Singh, "Power system harmonics research: A survey,” Eur. Trans.Electr. Power, vol. 19, no. 2, pp. 151-172, Aug. 2007.

[16] A. E. Emanuel, "Estimating the effects of harmonic voltage fluctuations on the temperature rise of squirrel-cage motors," IEEE Trans. Energy Convers., vol. 6, no. 1, pp. 161-168, Mar. 1991.

[17] C. J. Ramos, A. P. Martins, and A. S. Carvalho, "Rotor current controller with voltage harmonics compensation for a DFIG operating under unbalanced and distorted stator voltage," presented at the 33rd Annu. Conf. IEEE Ind. Electron. Soc., Taipei, Taiwan, China, Nov. 5-8, 2007.

[18] J. B. Hu, W. Zhang, H. S. Wang, Y. K. He, and L. Xu, "Proportional integral plus multi-frequency resonant current controller for grid-connected voltage source converter under imbalanced and distorted supply voltage conditions," J. Zhejiang Univ. SCI. A, vol. 10, no. 10, pp. 1532-1540, Dec. 2009.

[19] X. Yuan, W. Merk, H. Stemmler, and J. Allmeling, "Stationary-frame generalized integrators for current control of active power filters with zero steady-state error for current harmonics of concern current under unbalanced and distorted operating conditions," IEEE Trans. Ind. Appl.,vol. 38, no. 2, pp. 523-532, Mar./Apr. 2002.

[20] J. Hu and Y. He, "Modeling and control of grid-connected voltage-sourced converters under generalized unbalanced operation conditions," IEEE Trans. Energy Convers., vol. 23, no. 3, pp. 903-913, Sep. 2008.

[21] X. Guo, W. Wu, and Z. Chen, "Multiple complex-coefficient-filter based phase-locked loop and synchronization technique for threephase grid-interfaced converters in distributed utility networks,"IEEE Trans. Ind. Electron., [Online] Available: http://ieeexplore. ieee.org/xpls/pre_abs_all.jsp?isnumber=4387790\&arnumber=5409639,doi: 10.1109/TIE.2010.2041738.

[22] F. Peng, H. Akagi, and A. Nabe, "A new approach to harmonic compensation in power systems-A combined system of shunt passive and series active filters," IEEE Trans. Ind. Appl., vol. 26, no. 6, pp. 983-990, Nov./Dec. 1990.

[23] Dynamic Modeling and Improved Control of DFIG Under Distorted Grid Voltage Conditions ,Jiabing Hu, Member, IEEE, Heng Nian, Member, IEEE, Hailiang Xu, Student Member, IEEE, and Yikang He, Senior Member, IEEE. 